\title{
Spray-On Foam Insulations for Launch Vehicle Cryogenic Tanks
}

\author{
J. E. Fesmire ${ }^{1}$, B.E. Coffman ${ }^{1}$, B.J. Menghelli ${ }^{2}$, K.W. Heckle ${ }^{2}$ \\ ${ }^{1}$ Cryogenics Test Laboratory, NASA, Kennedy Space Center, FL USA \\ ${ }^{2}$ Cryogenics Test Laboratory, ASRC Aerospace, Kennedy Space Center, FL USA
}

\begin{abstract}
Spray-on foam insulation (SOFI) has been developed for use on the cryogenic tanks of space launch vehicles beginning in the 1960s with the Apollo program. The use of SOFI was further developed for the Space Shuttle program. The External Tank (ET) of the Space Shuttle, consisting of a forward liquid oxygen tank in line with an aft liquid hydrogen tank, requires thermal insulation over its outer surface to prevent ice formation and avoid in-flight damage to the ceramic tile thermal protection system on the adjacent Orbiter. The insulation also provides system control and stability with throughout the lengthy process of cooldown, loading, and replenishing the tank. There are two main types of SOFI used on the ET: acreage (with the rind) and closeout (machined surface). The thermal performance of the seemingly simple SOFI system is a complex of many variables starting with the large temperature difference of from 200 to 260 $\mathrm{K}$ through the typical $25-\mathrm{mm}$ thickness. Environmental factors include air temperature and humidity, wind speed, solar exposure, and aging or weathering history. Additional factors include manufacturing details, launch processing operations, and number of cryogenic thermal cycles. The study of the cryogenic thermal performance of SOFI under large temperature differentials is the subject of this article. The amount of moisture taken into the foam during the cold soak phase, termed Cryogenic Moisture Uptake, must also be considered. The heat leakage rates through these foams were measured under representative conditions using laboratory standard liquid nitrogen boiloff apparatus. Test articles included baseline, aged, and weathered specimens. Testing was performed over the entire pressure range from high vacuum to ambient pressure. Values for apparent thermal conductivity and heat flux were calculated and compared with prior data. As the prior data of record was obtained for small temperature differentials on non-weathered foams, analysis of the different methods is provided. Recent advancements and applications of SOFI systems on future launch vehicles and spacecraft are also addressed.
\end{abstract}

\section{Background}

Spray-on foam insulation (SOFI) materials were first developed in the 1960s including applications for the Saturn V moon rockets and subsequently the Space Shuttle. From a volumetric viewpoint, all space launch vehicles consist primarily of large tanks to contain the 
propellants. For example, the Space Shuttle's External Tank (ET) is comprised of a forward liquid oxygen $(90 \mathrm{~K})$ tank of 141,000 gallons capacity and an aft liquid hydrogen $(20 \mathrm{~K})$ tank of 383,000 gallons capacity (see Figure 1). These cryogenic propellant tanks and feed-lines must be thermally insulated to prevent or minimize, according to specific requirements, the condensation of air or the formation of ice and otherwise provide sufficient isolation from the ambient environment. The thermal insulation system is designed to meet three conjoined areas of requirements: safety, control, and flight performance. Safety aspects include the prevention of excessive ice formation or liquid air condensate that could present a debris hazard or an enhanced flammability problem. Control during pre-launch loading operations is of course vital for successful cooldown, tanking, stabilization, and replenishment within the time constraints of the mission. The insulation system provides the added benefit of reducing the continuous boiloff losses of the cryogenic propellants. Flight performance requirements include thermal protection of the vehicle tanks from radiant heating or aerodynamic effects.
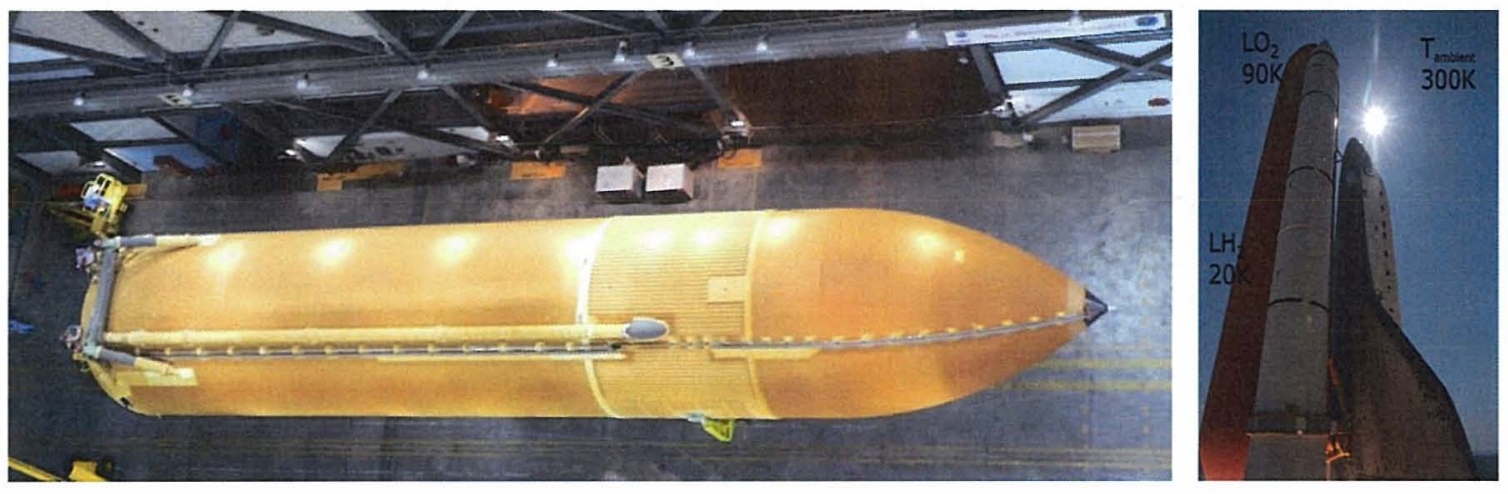

Figure 1. A view of the Space Shuttle External Tank in the Vehicle Assembly Building (left) and in flight (right).

Other cryogenic tank insulation materials used in the past include rigid foams and cork. For some vehicles, the liquid oxygen tanks have been left bare; the insulation in this case is layers of frost from the humid air surrounding the vehicle on the launch pad. Cryogenic propellant loading operations can take from several hours up to around 12 hours. Provision must also be made for unloading the vehicle for a scrub and repeat loading at some later date. This thermal cycling is an important design parameter for the mechanical behavior of the insulation and must be carefully considered to avoid adverse consequences such as cracking or delamination from the tank wall.

The objective of the tank insulation system is to reduce heat flux to acceptable levels while providing consistent performance at the least total system mass. Effective thermal conductivity [k-value, $\mathrm{mW} / \mathrm{m}-\mathrm{K}]$ is the overall measure of the thermal performance per unit thickness of insulation material. The variations of apparent thermal conductivity (k-value) with cold vacuum pressure for different cryogenic insulation materials are shown in Figure 2. ${ }^{1,2}$ The boundary conditions are approximately $293 \mathrm{~K}$ and $77 \mathrm{~K}$ and the residual gas is nitrogen. There are two main regions of interest for space launch and exploration applications: ambient pressure (nonvacuum) and high vacuum. Although the non-vacuum application is of primary interest, SOFI applications for in-space cryogenic storage are also of interest. In such cases where the cryogenic tanks are loaded on the launch pad, a composite system of materials that offer both non-vacuum and high-vacuum performance must be devised. Figure 2 illustrates the extreme thermal performance difference between these two cases. Even though aerogel blankets may be twice 
better than SOFI at the ambient pressure, the performance of a typical multilayer insulation (MLI) system is yet 100 times better. ${ }^{3}$ However, MLI cannot be used in an open ambient, humidair environment while the aerogel blanket is fully hydrophobic and well-suited for such exposures. ${ }^{4}$ Therefore, the proper design and selection of insulation materials depends strongly on the environmental parameters.

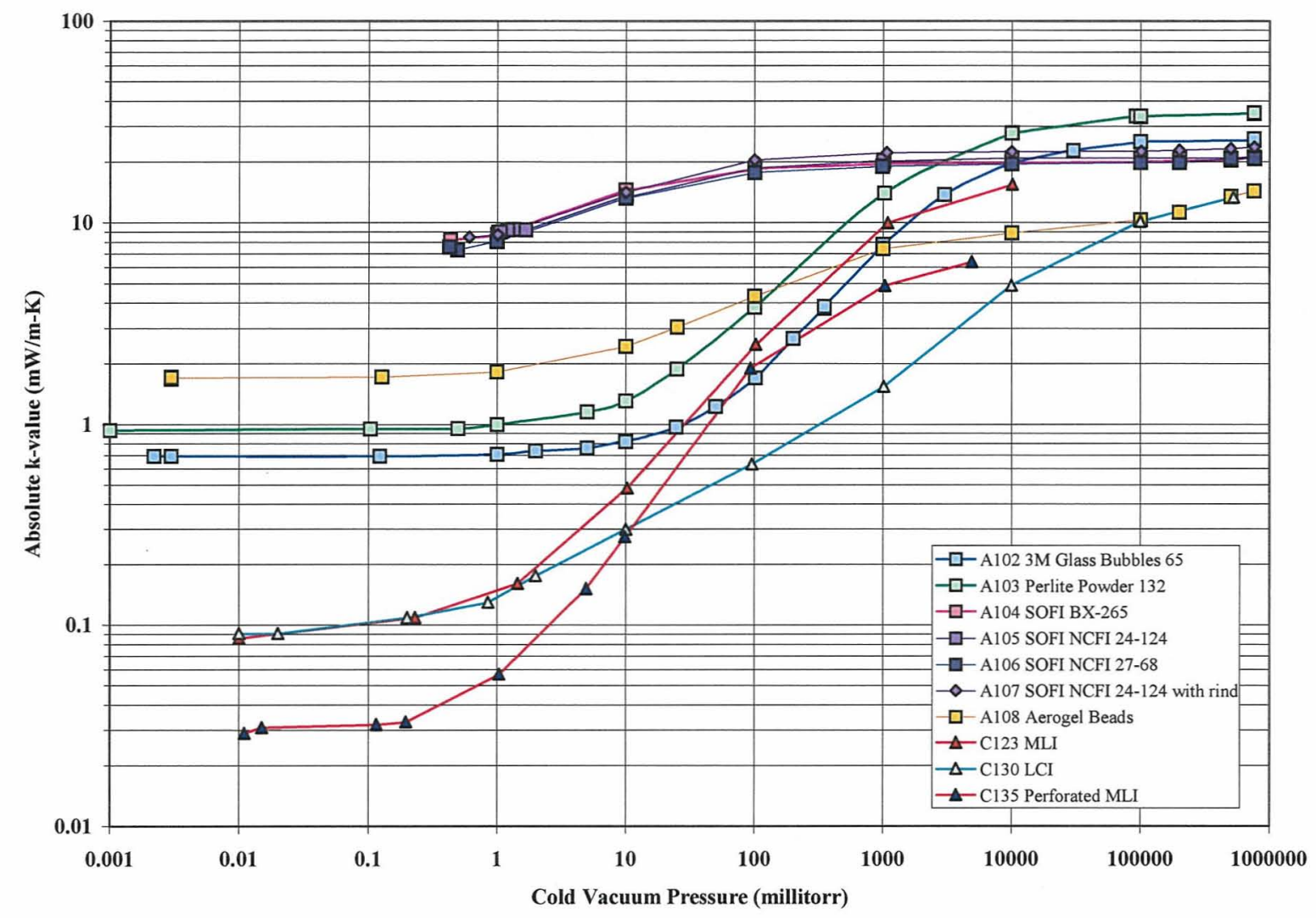

Figure 2. Variation of apparent thermal conductivity (k-value) with cold vacuum pressure for different cryogenic insulation materials at the boundary conditions of approximately $293 \mathrm{~K}$ and $77 \mathrm{~K}$ (the residual gas is nitrogen).

\section{Introduction}

The well-developed, modern SOFI materials have an extraordinary combination of mechanical and thermal properties in addition to being light in weight. The main limitations are those of weathering exposure and repeated thermal cycling. The uses are therefore for generally one-time-use vehicle tanks. Reusable space launch vehicles will likely require an insulation and thermal protection approach that is not based on SOFI technology.

These foam systems are complex chemical formulations with a host of complicating factors requiring extensive physical and chemical testing as well as characterization through analysis and modeling. Most of the data produced are based on baseline (not aged or weathered) foams. Data from tests that do include some aging or weathering exposure are generally done without imposing a large temperature difference from cryogenic to ambient. 
A comprehensive experimental study, Long-Term Moisture/Aging Study of SOFI under Actual-Use Cryogenic-Vacuum Conditions, was conducted to investigate the thermal performance of SOFI under simulated actual-use conditions. ${ }^{5}$ The study included the following elements: environmental exposure testing (aging and weathering), thermal conductivity testing under both cryogenic-vacuum and ambient conditions, physical characterization of materials, cryogenic moisture uptake testing under actual-use conditions, and fire chemistry testing. This study was part of a larger project entitled Technologies to Increase Reliability of Thermal Insulation Systems for space launch and exploration applications. ${ }^{6}$ The testing described in this report is focused primarily on the thermal performance of SOFI under the representative operational conditions of a large temperature difference. Materials are tested after both aging and weathering exposures. Experimental results on cryogenic moisture uptake and fire chemistry are previously reported.

\section{Materials}

Foam materials were sprayed at NASA's Marshall Space Flight Center in accordance with nominal flight specifications. ${ }^{8,9}$ Baseline (new condition) specimens were allowed to cure for approximately one month. Several $610 \mathrm{~mm}$ x $610 \mathrm{~mm}$ samples of the three types of foam, NCFI 24-124 (used on the existing nine stored External Tanks), NCFI 27-68 (formerly proposed alternative acreage foam), and BX-265 (closeout foam), were packaged and shipped to KSC. The $610 \mathrm{~mm}$ x $610 \mathrm{~mm}$ samples of foam were then machined into $203 \mathrm{~mm}$ diameter test specimens of 25 or $32 \mathrm{~mm}$ thickness. The measured densities of all specimens were comparable, ranging from 37 to $40 \mathrm{~kg} / \mathrm{m}^{3}$ prior to testing.

Environmental exposure of the SOFI materials was an integral part of the performance testing. The aging and weathering simulations were performed at two exposure sites. The KSC Vehicle Assembly Building was used for the aging test (see Figure 3). The aging site simulates the area where the External Tank is stored before the vehicle stacking and launch preparations begin. The conditions in this area are mild with ambient humidity levels and no direct sunlight. The Corrosion Beach Site at KSC was used for the weathering test as shown in Figure 4. The weathering site simulates the conditions that a mated External Tank is exposed to while it is on the pad awaiting launch. The aging time for an External Tank can be several years whereas the typical weathering exposure is about one month. The maximum weathering exposure, as recorded in the Shuttle flight history, is about six months. ${ }^{10}$ The test specimen mounting enclosure, shown in fig. 3 (right), was designed to expose only the center portion of the top face of the material. Figure 4 (right) shows a SOFI test specimen type NCFI 24-124 after only one month of weathering. Exposure time durations are as follows: baseline, 2 weeks, 1 month, 3 months, 6 months, 12 months, 18 months, and 2 years.

In addition, a total of five 1-m long cylindrical clam shell test articles were produced for testing by means of a cylindrical thermal conductivity test instrument (Cryostat-100). The specifications for these cylindrical test articles of approximately $25-\mathrm{mm}$ thickness are given in Table 1. Photographs of one of the BX-265 test articles are shown in Figure 5. The test articles composed of SOFI material 24-124 include a specimen that is machined (shaved) and one that is in the net spray condition (rind). 

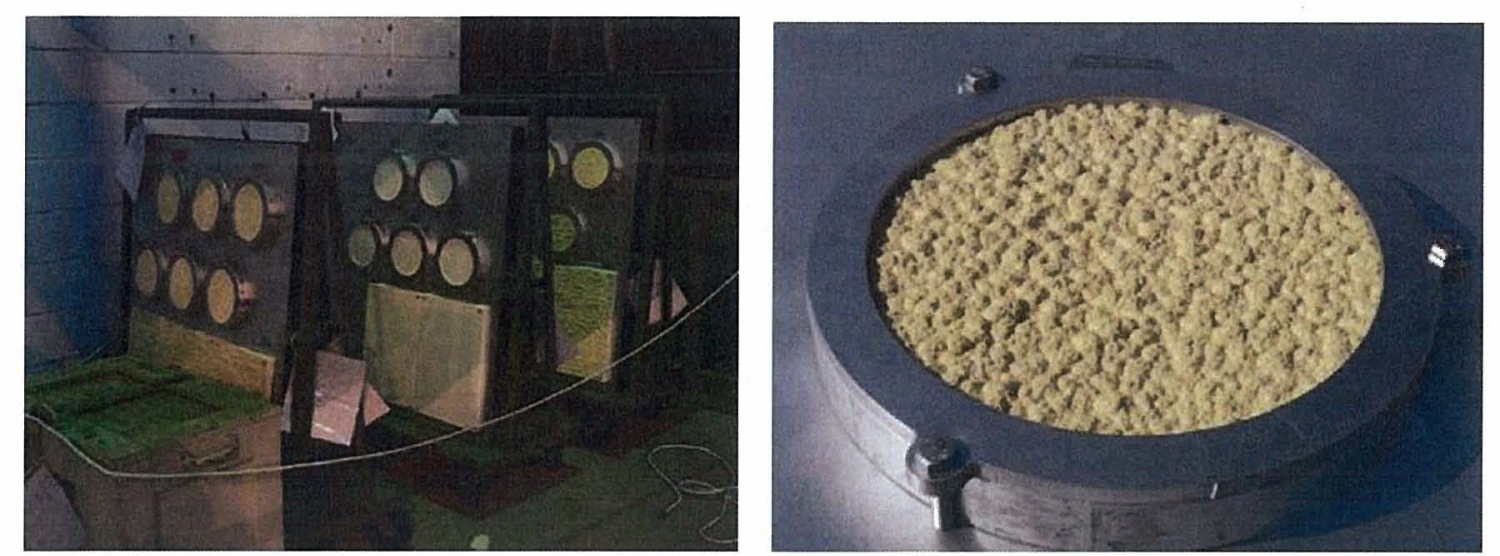

Figure 3. Aging of SOFI test specimens inside the Vehicle Assembly Building at Kennedy Space Center (left). The mounting enclosure is shown on the right.
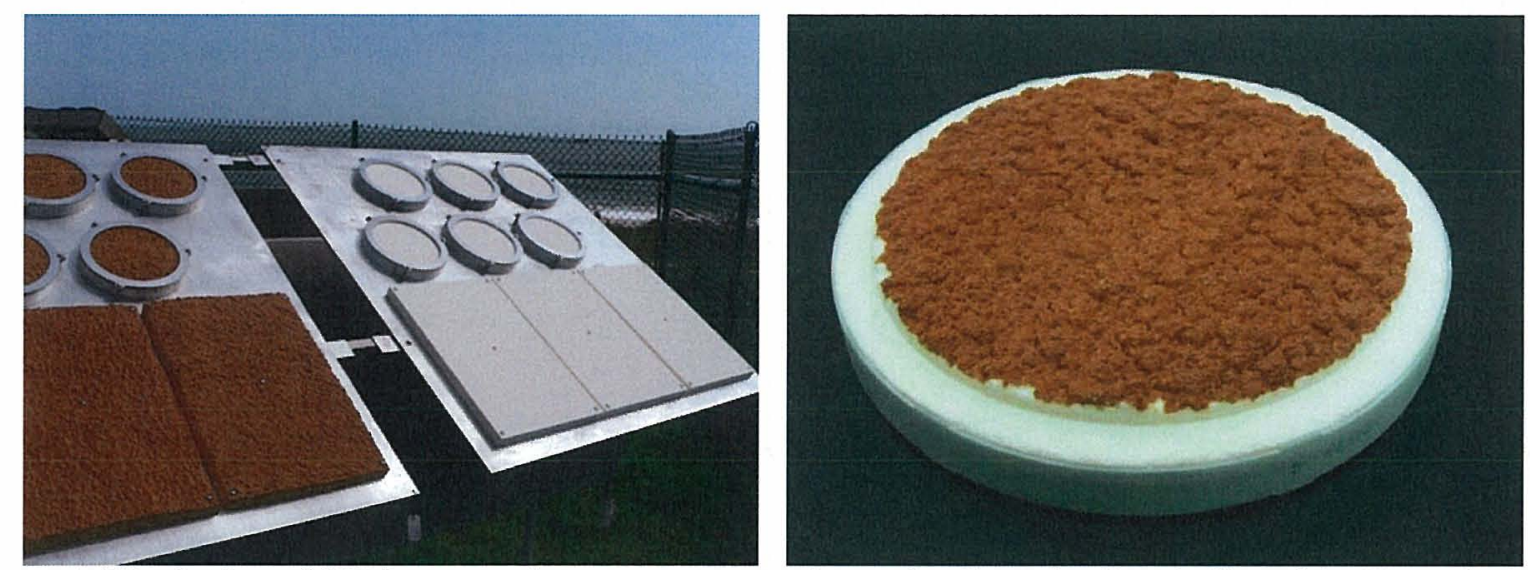

Figure 4. Weathering of SOFI test specimens exposure testing at the Corrosion Beach Site of the Kennedy Space Center (left). A one-month weathered specimen is shown on the right.

Table 1. Specifications of 1-m long cylindrical clam shell test articles.

\begin{tabular}{|c|l|l|c|c|c|}
\hline Ref. No. & \multicolumn{1}{|c|}{ Material } & Outer surface & $\begin{array}{c}\text { Date } \\
\text { Sprayed }\end{array}$ & $\begin{array}{c}\text { T }_{\text {final }} \\
\mathrm{m} \mathrm{m}\end{array}$ & $\begin{array}{c}\text { Density } \\
\mathrm{g} / \mathrm{cc}\end{array}$ \\
\hline N/A & B X -265 & Shaved & $3 / 31 / 2005$ & 24.1 & 0.044 \\
A 104 & B X -265 & Shaved & $4 / 6 / 2005$ & 26.70 & 0.042 \\
A 107 & N C F I 24-124 & Rind (Partial) & $5 / 11 / 2005$ & 23.90 & 0.038 \\
A 105 & N C F I 24-124 & Shaved & $6 / 9 / 2005$ & 25.60 & 0.038 \\
A 106 & N C F I 27-68 & Shaved & $7 / 6 / 2006$ & 24.40 & 0.037 \\
\hline
\end{tabular}



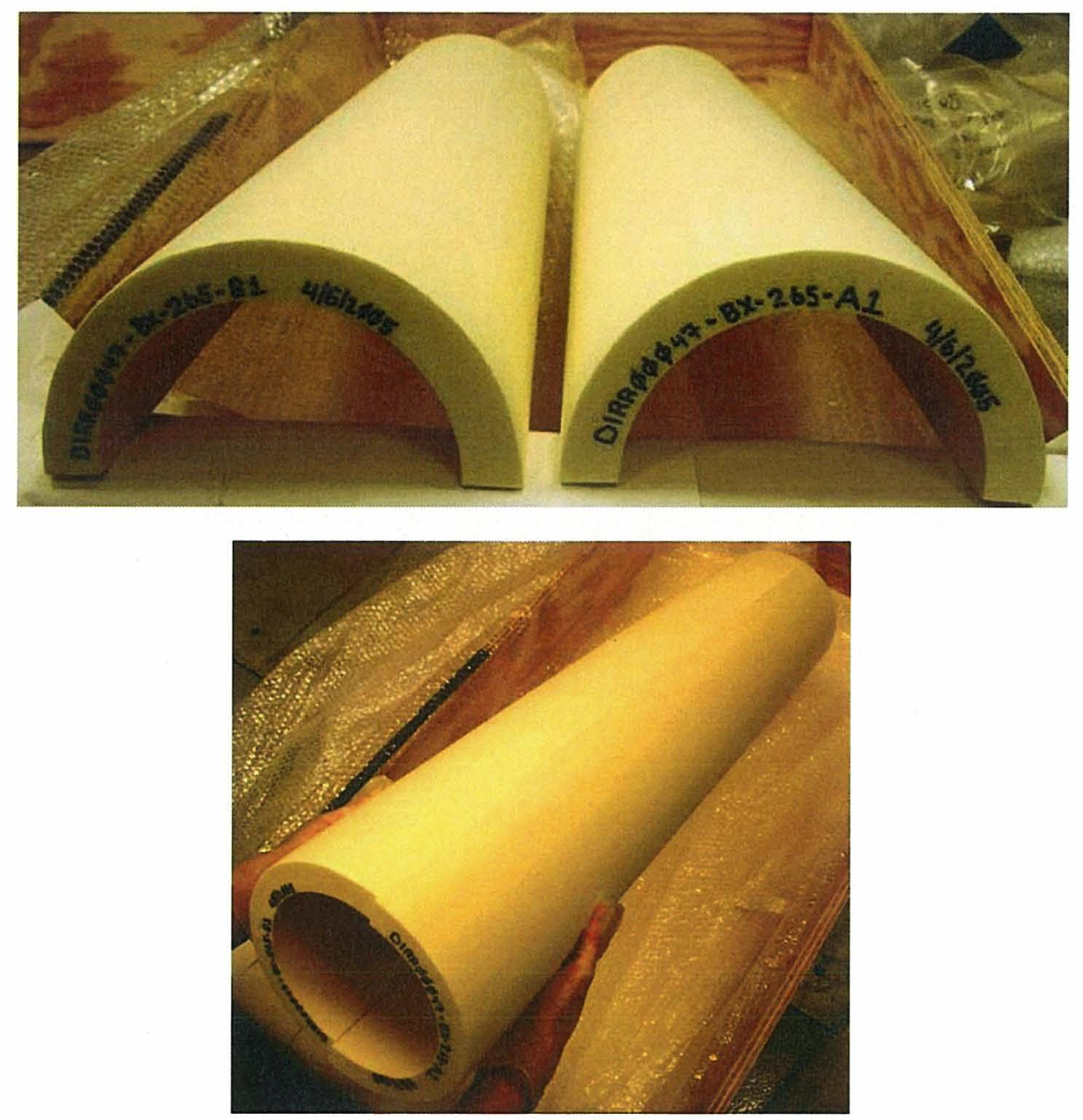

Figure 5. One of five 1-m long cylindrical clam shell test articles were produced for testing using a cylindrical thermal conductivity test instrument (Cryostat-100). Machined thickness of approximately $25-\mathrm{mm}$ is shown in the top view while the precise longitudinal fit-up is shown in the bottom view.

\section{Experimental test methods}

The Cryostat-100 instrument uses the steady-state liquid nitrogen boiloff (evaporation rate) calorimeter method to determine apparent thermal conductivity (k-value) and heat flux. ${ }^{11}$ Preparations of the test article included installing temperature sensors through the thickness of the insulation at approximate $6.4 \mathrm{~mm}$ intervals. The two halves of the SOFI test article were secured tightly in place by using a series of four stainless steel band clamps as shown in Figure 6. Thin PVC plastic foils were positioned underneath the band clamps to prevent damage to the foam. Finally, three temperature sensors were affixed to the outer surface of the test article. Fitup to the cold mass was precise in the first case with the BX-265 test article; there were no visible gaps or deformities at the two longitudinal seams. The remaining test articles each had gaps less than about $4 \mathrm{~mm}$ which were filled with fiberglass insulation material to complete the installation. Photographs of the two NCFI 24-124 test articles installed and ready for testing are shown in Figure 7. 

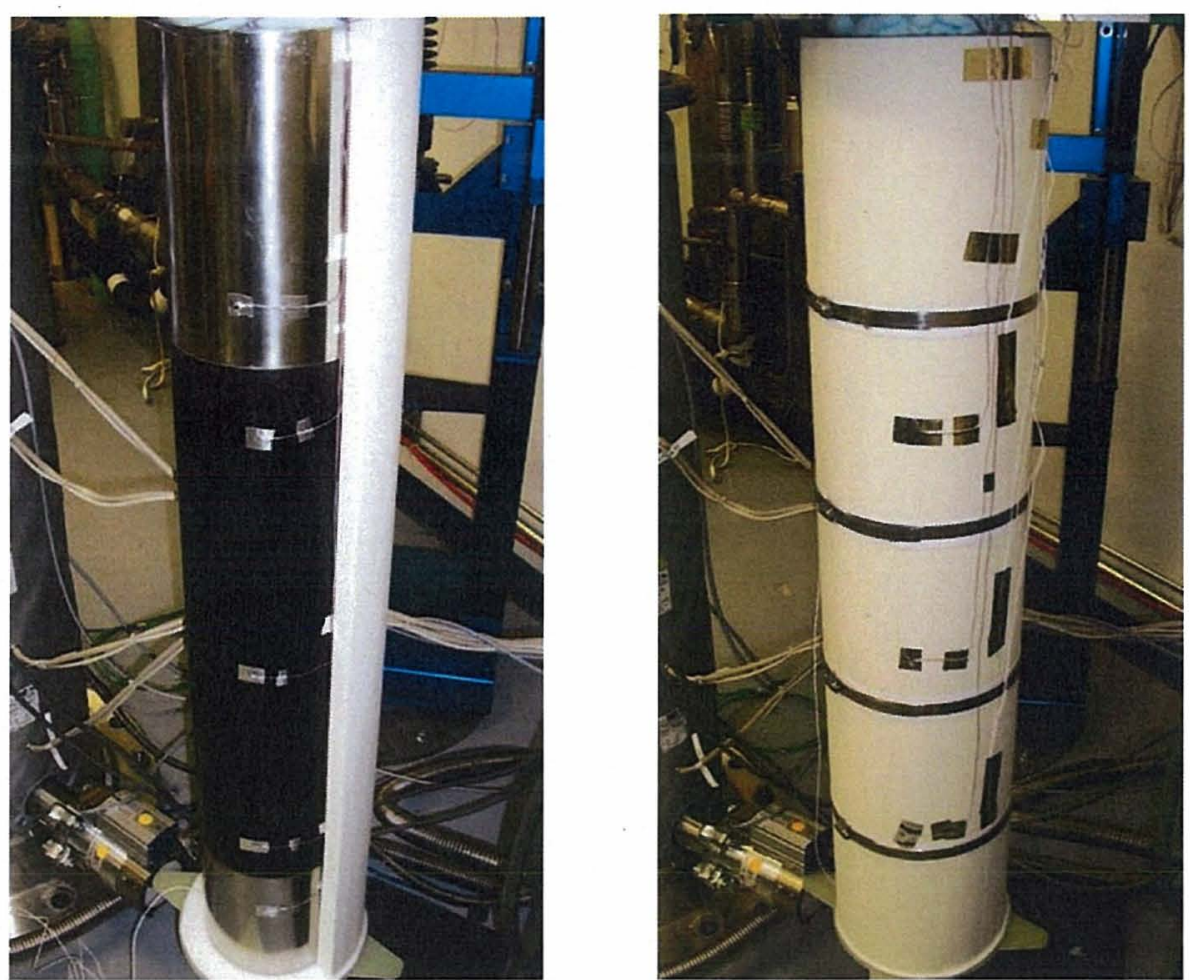

Figure 6. Installation of a SOFI clam-shell test article on the cold mass assembly of thermal conductivity instrument Cryostat-100.
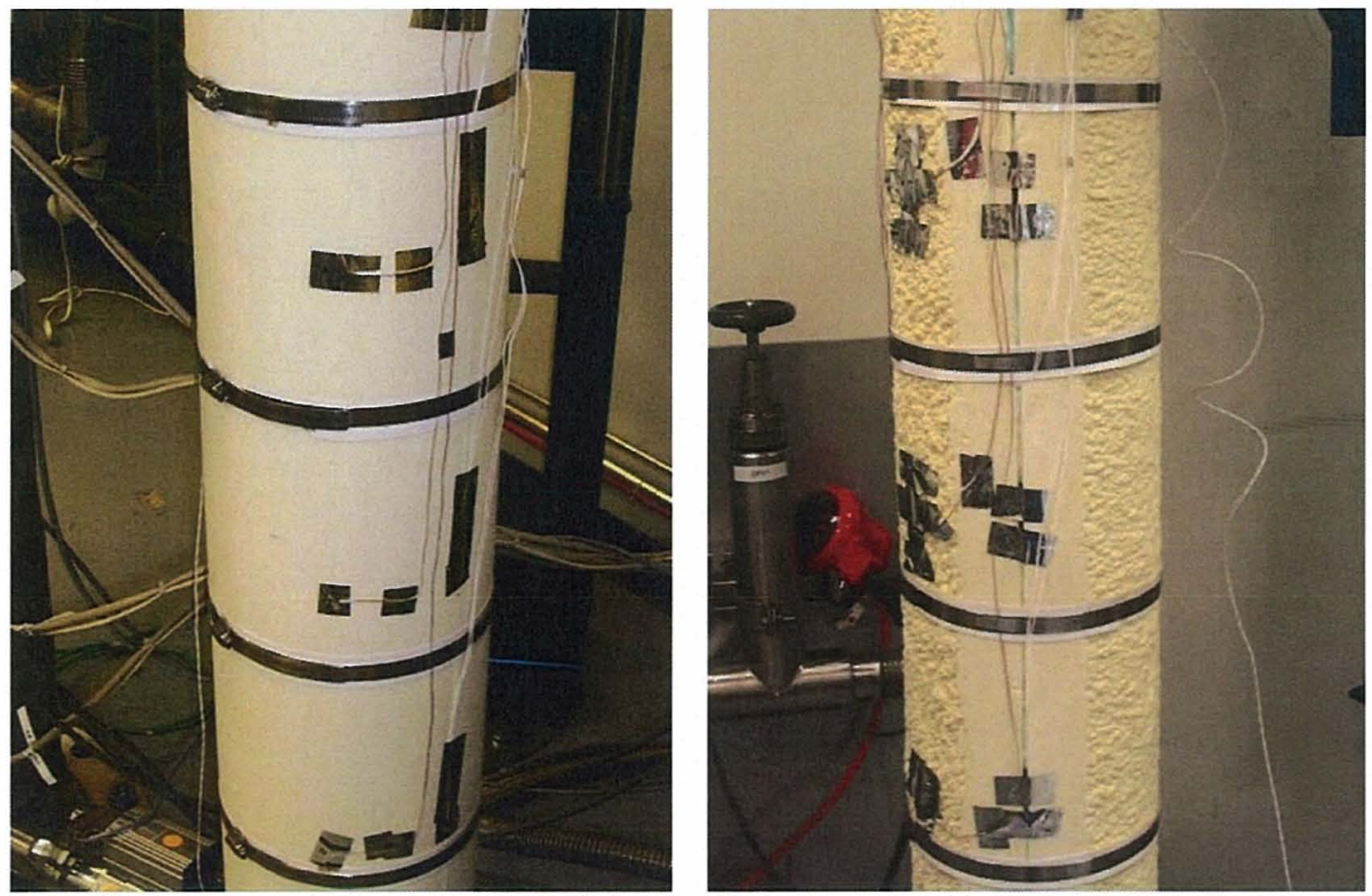

Figure 7. Installed Cryostat-100 insulation test articles installed: NCFI 24-124 shaved (left) and NCFI 24-124 with rind (right). 
A satisfactory cryostat test is defined as the steady-state heat leak rate (watts) through the specimen at a prescribed set of environmental conditions, including a stable warm-boundary temperature (WBT), a stable cold-boundary temperature (CBT), and a cold vacuum pressure (CVP). A minimum of eight CVP test points are obtained for each test article. A liquid nitrogen cold mass maintains the CBT at approximately $78 \mathrm{~K}$. The WBT is maintained at approximately $293 \mathrm{~K}$ using an external heater with an electronic controller. The delta and mean temperatures are therefore $215 \mathrm{~K}$ and $185 \mathrm{~K}$, respectively. Vacuum levels cover the full range from high vacuum (HV) (below $1 \times 10-4$ torr) to soft vacuum (SV) ( 1 torr) to no vacuum (NV) (760 torr). The residual gas is nitrogen and testing proceeded in a step-wise progression from NV to HV.

The rate of the heat transfer, $\mathrm{Q}$, through the insulation system into the cold-mass tank is directly proportional to the flow rate of liquid nitrogen boiloff as shown by equation (1). The flow rate is measured by a mass flow meter connected to a data acquisition system. The average boiloff flow rate is taken as the average over a calculated test chamber liquid level from 92 to 88 percent full. In measuring the flow rate, the back-pressure from the flow meter and connecting tube is approximately $0.1 \mathrm{psig}$. This pressure, taken as the saturation pressure of the cryogen, corresponds to a heat of vaporization of $198.6 \mathrm{~J} / \mathrm{g}$ for liquid nitrogen. The k-value $\left(\lambda_{\mathrm{k}}\right)$ is determined from Fourier's law for heat conduction through a cylindrical wall as given in equation (2). The symbols used in these equations are given in Table 2.

$$
\begin{aligned}
Q=V_{S T P} \rho_{S T P} h_{f g}\left(\frac{\rho_{f}}{\rho_{f g}}\right) \\
\lambda_{\mathrm{k}}=\frac{Q \ln \left(\frac{R_{o}}{R_{i}}\right)}{2 \pi L_{e f f} \Delta T}
\end{aligned}
$$

Table 2. Symbols Used for Calculation of Thermal Properties from Boiloff Testing

\begin{tabular}{lll} 
Symbol & Description & Unit \\
\hline$V$ & Volumetric Flow Rate & $\mathrm{cm}^{3} / \mathrm{s}$ \\
$\rho$ & Density of Gaseous Nitrogen & $\mathrm{g} / \mathrm{cm}^{3}$ \\
$\mathrm{~h}_{\mathrm{fg}}$ & Heat of Vaporization & $\mathrm{J} / \mathrm{g}$ \\
$\mathrm{R}_{\mathrm{o}}$ and $\mathrm{R}_{\mathrm{i}}$ & Radius of Insulation, outer and inner & $\mathrm{m}$ \\
$\mathrm{L}_{\mathrm{eff}}$ & Length, effective heat transfer (cylindrical) & $\mathrm{m}$ \\
$\mathrm{A}_{\mathrm{eff}}$ & Area, effective heat transfer area & $\mathrm{m}^{2}$ \\
$\Delta \mathrm{T}$ & WBT - CBT & $\mathrm{K}$ \\
\hline
\end{tabular}


The mean heat flux is calculated by dividing the total heat transfer rate $(\mathrm{Q})$ by the effective heat transfer area $\left(\mathrm{A}_{\mathrm{eff}}\right)$. Further details on the heat transfer calculations as well as uncertainty analyses for the apparatus have been previously reported. ${ }^{12} \mathrm{~A}$ total error of 3.2 percent has been calculated for this test apparatus. Figure 8 gives a simplified schematic of the Cryostat-100 instrument as well as a photograph of a completed SOFI test article ready for placement into the vacuum can assembly.

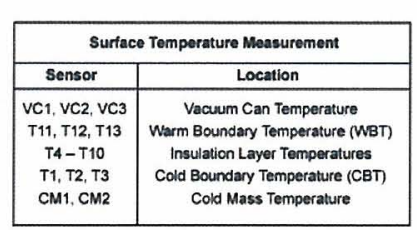

Figure 8. Simplified schematic of Cryostat-100, left, showing typical locations of temperature sensors. Photo on right shows completed test article and cold-mass assembly adjacent to the vacuum can assembly.

Thermal performance testing under ambient room temperature and pressure conditions provides both a baseline and a reference for comparison with other materials. Thermal conductivity $(\lambda)$ testing under ambient conditions of both new and aged specimens (26 specimens and a total of 30 tests) was performed in accordance with standard test method ASTM C518. ${ }^{13}$ The instrument used was a Netzsch Lambda 2300F heat flux meter. The average boundary temperatures are $307 \mathrm{~K}$ (upper plate) and $286 \mathrm{~K}$ (lower plate) for a mean temperature $\left(T_{m}\right)$ of $297 \mathrm{~K}$. A specimen holder was built to accommodate the $203-\mathrm{mm}$ diameter round specimens. The holder consisted of a $305-\mathrm{mm}$ by $305-\mathrm{mm}$ frame constructed of a SOFI foam material (BX-265) and featuring a cut-out as shown in Figure 9. Preparation of the test specimens included removal of the approximate 6-mm thick rind for both the NCFI 24-124 and NCFI 27-68 materials or removal of any indentations for the BX-265 material. That is, all specimens were machined to a smooth surface finish to a thickness of approximately $25-\mathrm{mm}$ or less. 

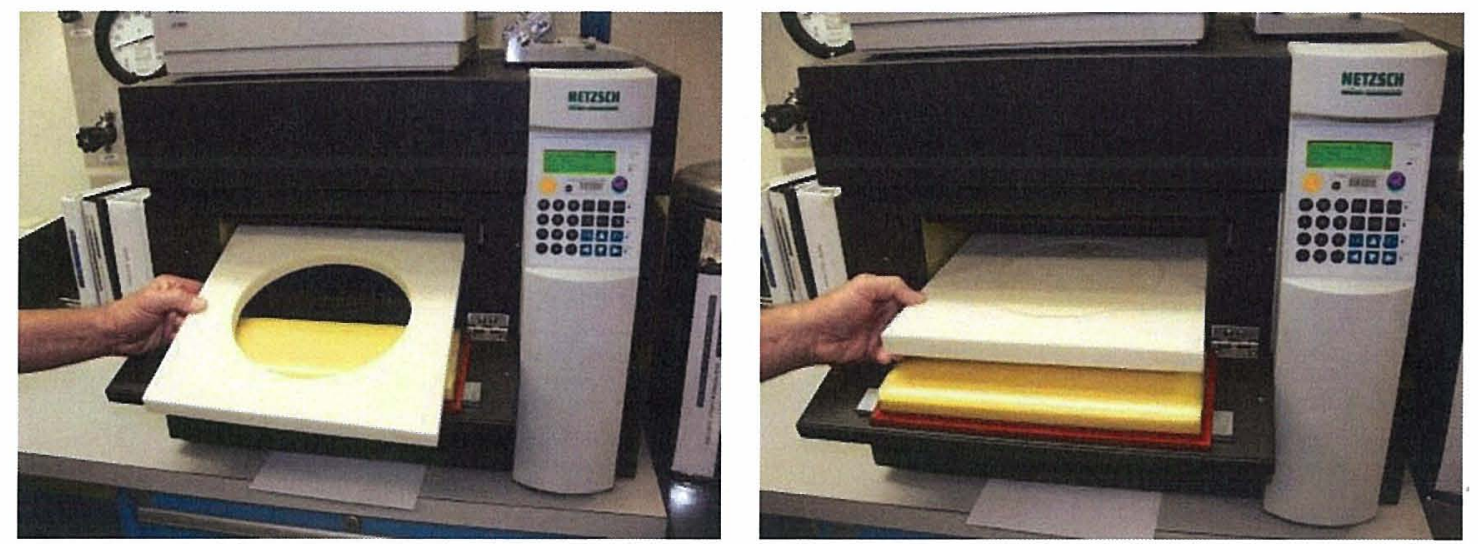

Figure 9. Specimen holding frame for heat flux meter testing (left); test specimen being installed for testing (right).

Physical characterization tests included percent open-cell content and surface area (and pore size). Testing for open cell content was performed in accordance with ASTM D-6226 using a Quantachrome Instruments UltraFoamTM pycnometer. ${ }^{14}$ These tests were performed at ambient temperature. Surface area testing was performed using a Quantachrome Instruments NovaTM surface area analyzer. These tests were performed under vacuum in sequence with LN2 bath immersion in accordance with standard laboratory methods.

\section{Results}

\subsection{Cryogenic Thermal Performance}

Cryogenic thermal performance testing included a total of over 100 tests of four baseline (new condition) test specimens using Cryostat-100 (absolute apparent thermal conductivity, kvalue). A graphical summary of the results is presented in Figure 10. The k-values for the baseline foam materials ranged from $21.1 \mathrm{~mW} / \mathrm{m}-\mathrm{K}$ at ambient pressure to approximately 7.5 $\mathrm{mW} / \mathrm{m}-\mathrm{K}$ at high vacuum. The alternate acreage foam NCFI 27-68 showed the lowest thermal conductivity overall with a k-value of $20.7 \mathrm{~mW} / \mathrm{m}-\mathrm{K}$ at 760 torr and 7.3 at 0.5 millitorr. Thermal conductivities for the three foams were found to be in a close range from 20.9 to $21.1 \mathrm{~mW} / \mathrm{m}-\mathrm{K}$. Heat flux was in the range from approximately 70 to $170 \mathrm{~W} / \mathrm{m}^{2}$ for the vacuum and no vacuum conditions, respectively, for the typical $25-\mathrm{mm}$ thickness test articles.

There are multiple test points at each cold vacuum pressure for all materials. The multiple points are not shown for clarity as the variation was typically less than 1 percent. The multiple test points are shown in Figure 11 for the 760 torr (no vacuum) cases as this test condition is generally the most important for space launch vehicle applications.

The results of rind (net spray) versus machined for the foam material NCFI 24-124 are presented in Figure 12. The k-value was found to be significantly higher (13 percent) at the no vacuum condition and approximately the same under vacuum condition. Although the average thicknesses were about the same, the thickness was not entirely uniform for the rinded test article as it was for the machined test article. 
Because these foam materials include a blowing agent and are approximately 95 percent closed cell, the order of testing in vacuum was considered. A special series of tests was performed to understand if evacuation and subsequent re-pressurization of the foam with nitrogen (or air) would have a noticeable effect on the thermal conductivity under cryogenicvacuum conditions. The test article was SOFI BX-265 and the results are given in Figure 13. No significant effect was found which allowed a more flexible test methodology for obtaining the multiple data points through the Cryostat-100 test program.

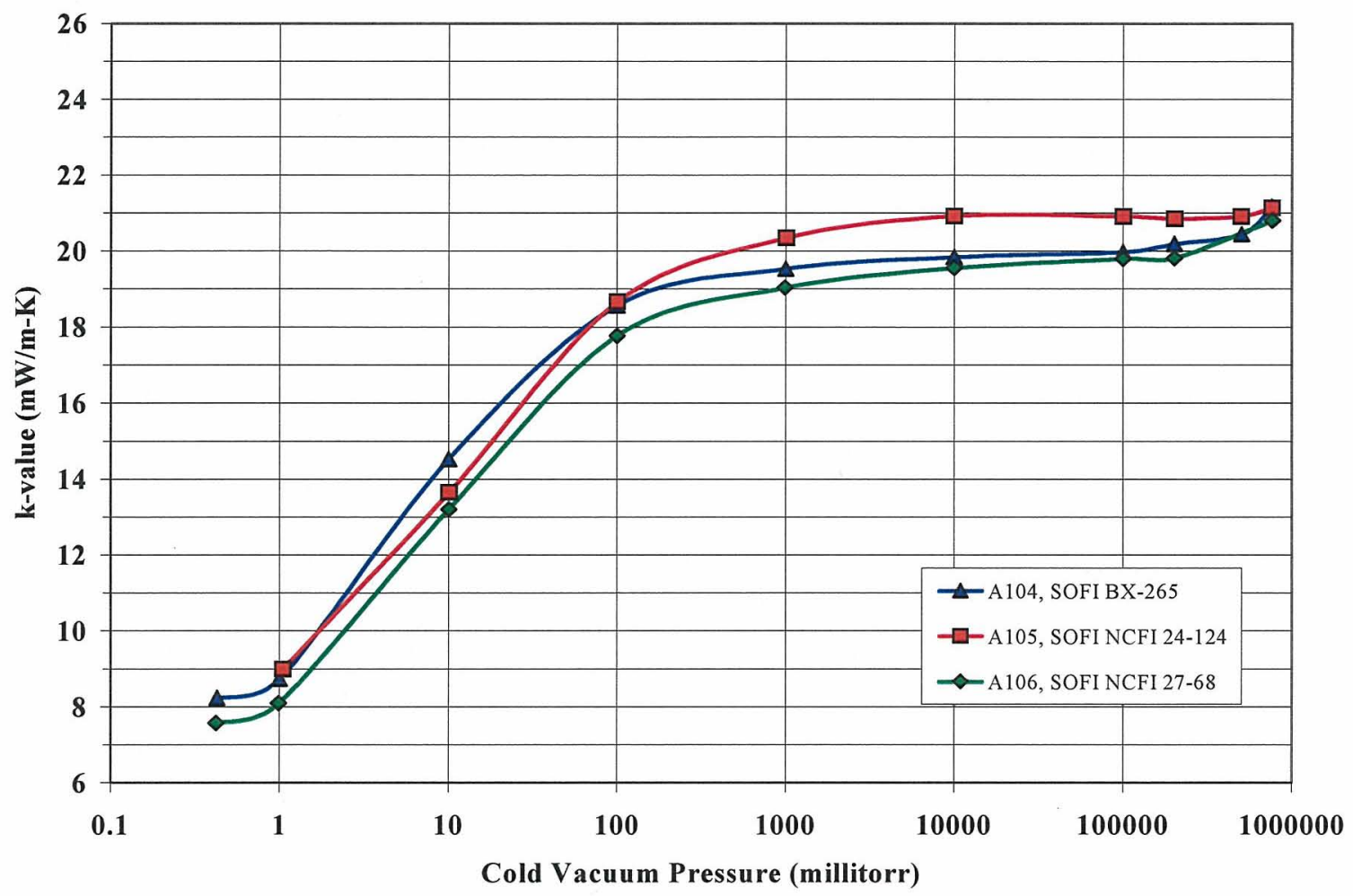

Figure 10. Variation of apparent thermal conductivity (k-value) with cold vacuum pressure for three different SOFI materials. Boundary temperatures are approximately $293 \mathrm{~K}$ and $78 \mathrm{~K}$. The residual gas in nitrogen. 


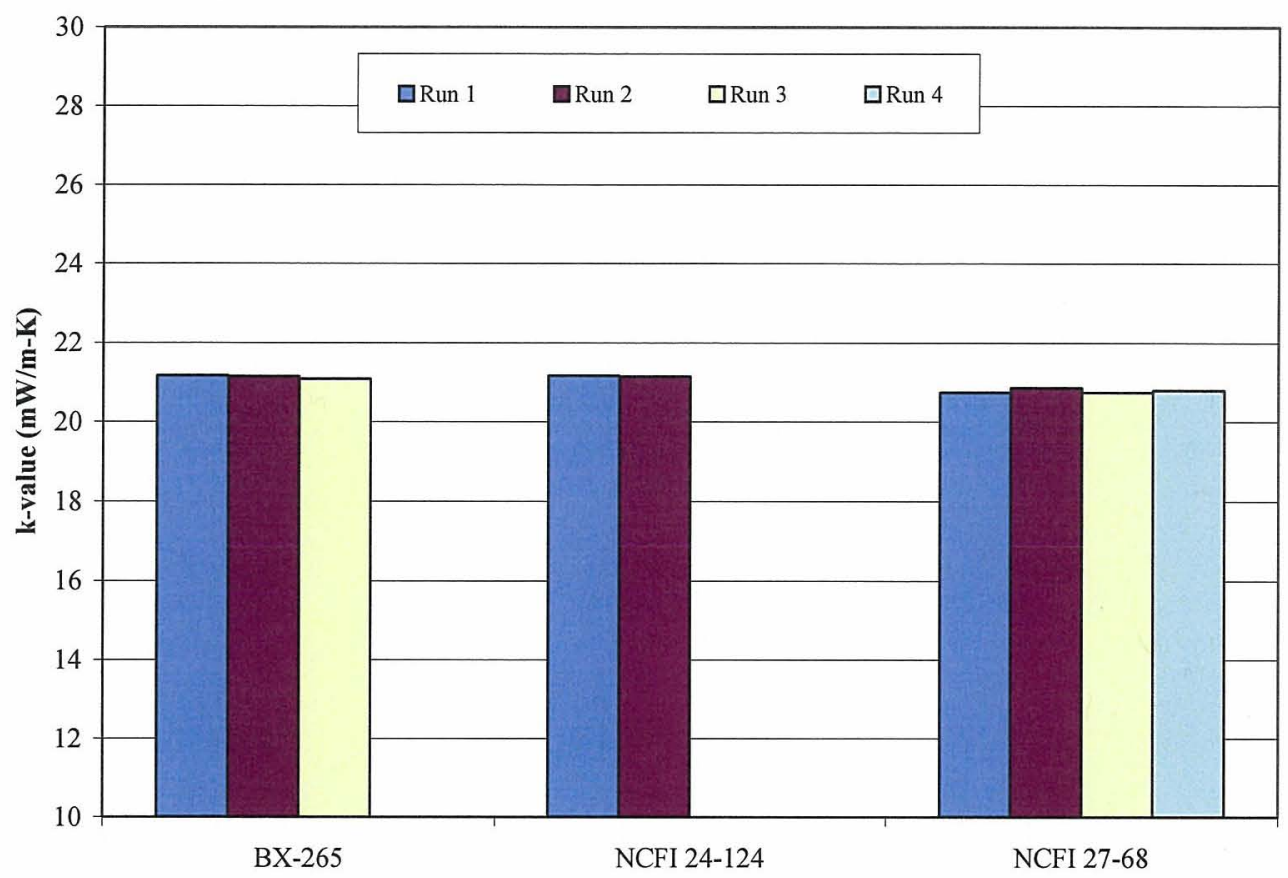

Figure 11. Apparent thermal conductivity (k-value) of SOFI materials at a cold vacuum pressure of 760 torr (no vacuum) gaseous nitrogen. Boundary temperatures are approximately $293 \mathrm{~K}$ and $78 \mathrm{~K}$.

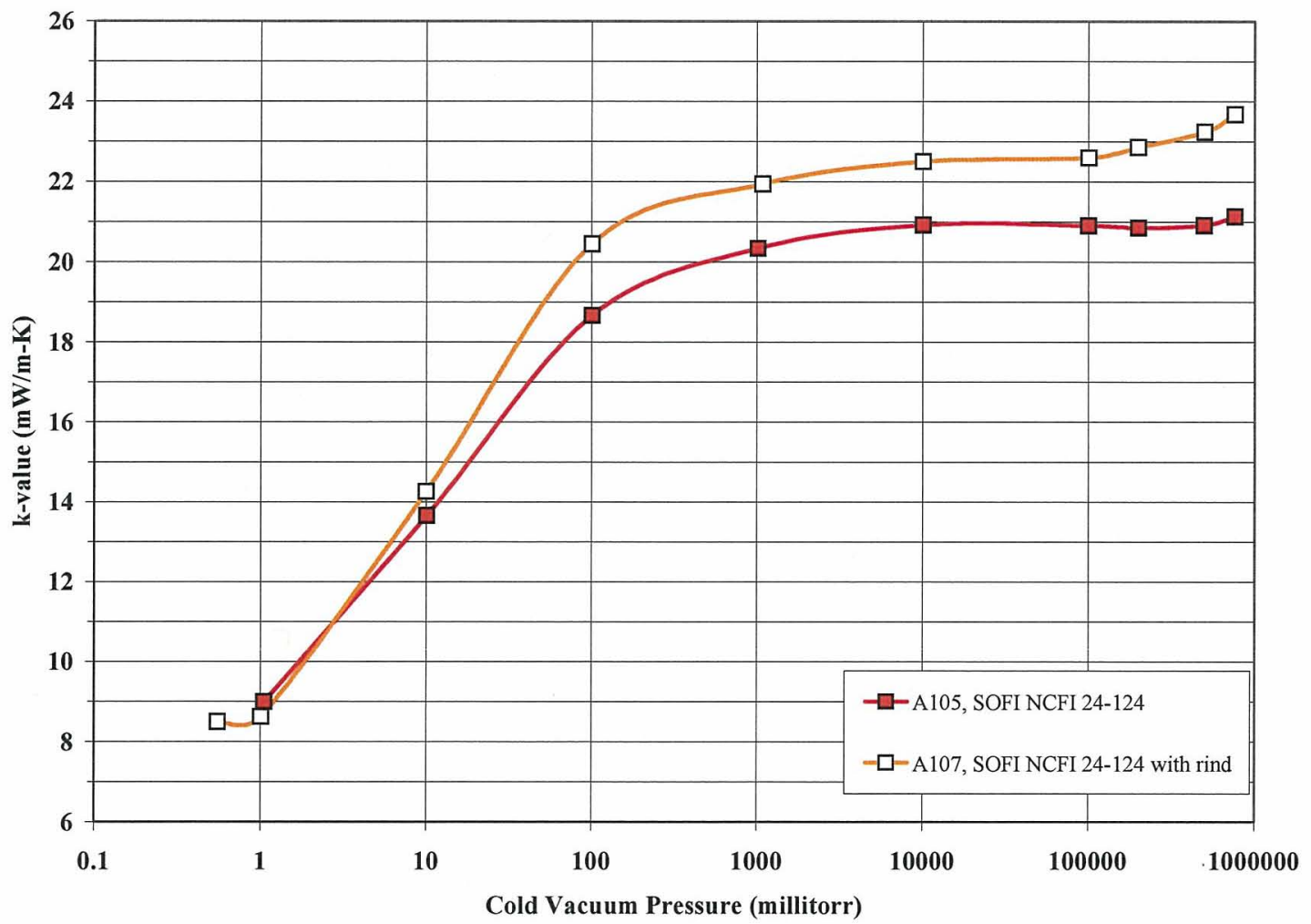

Figure 12. Variation of apparent thermal conductivity (k-value) with cold vacuum pressure for SOFI material 24124 shaved and with rind. Boundary temperatures are approximately $293 \mathrm{~K}$ and $78 \mathrm{~K}$. The residual gas in nitrogen. 


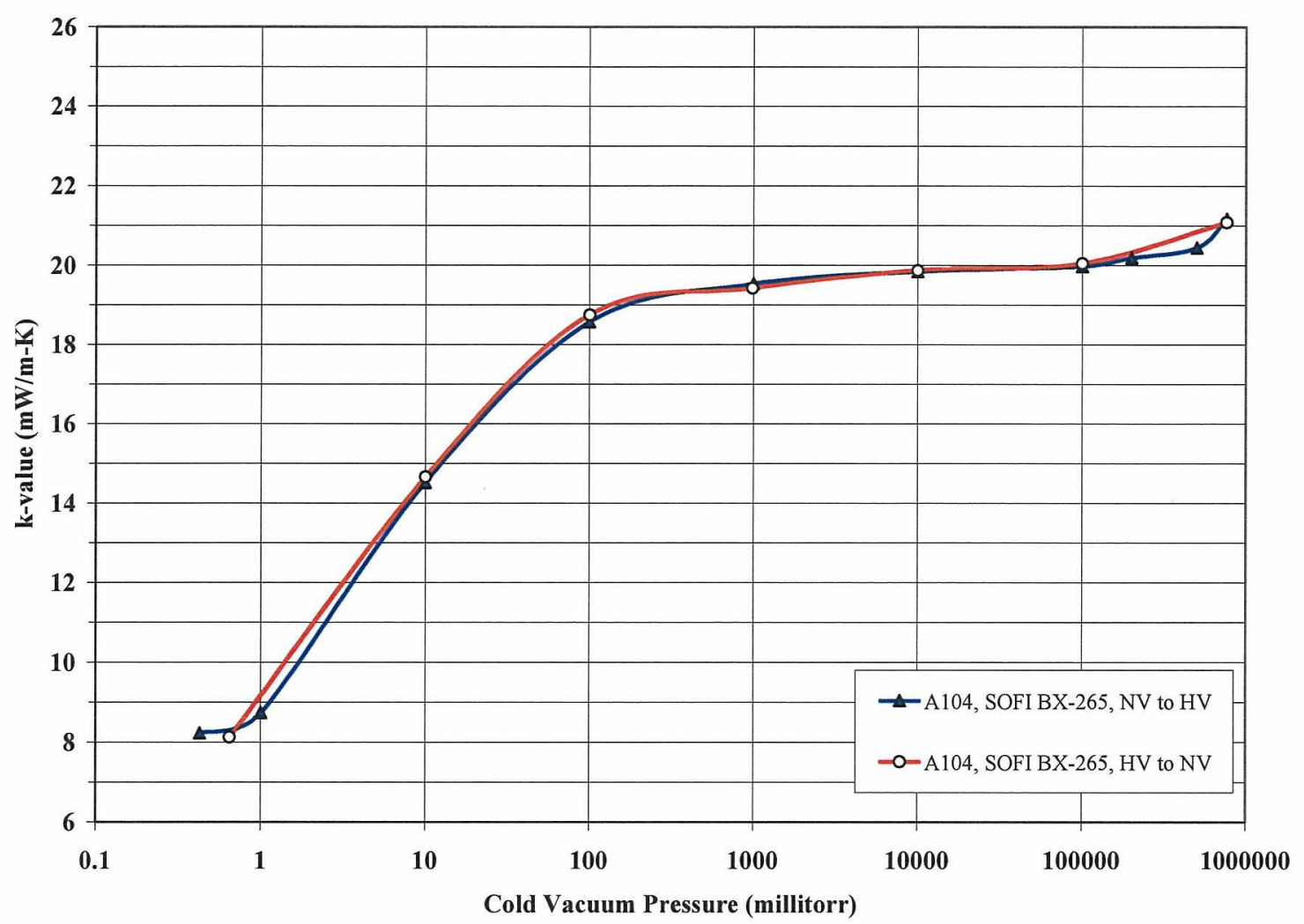

Figure 13. Variation of apparent thermal conductivity (k-value) with cold vacuum pressure for SOFI material BX265 tested from no vacuum to high vacuum and from high vacuum to no vacuum. Boundary temperatures are approximately $293 \mathrm{~K}$ and $78 \mathrm{~K}$. The residual gas in nitrogen.

\subsection{Ambient Thermal Conductivity}

The ambient thermal conductivities $(\lambda)$ ranged from $19 \mathrm{~mW} / \mathrm{m}-\mathrm{K}$ (baseline) to $32 \mathrm{~mW} / \mathrm{m}-\mathrm{K}$ (aged). The results for aging of BX-265 and NCFI 24-124 are given in Figure 14 while the results for weathering are summarized in Figure 15. Results show that the actual thermal performance is significantly degraded from exposure durations of up to 24 months with the sharpest change occurring within the first six months of aging or weathering. Compared to the aged specimens, the weathered specimens showed higher thermal conductivities as expected. However, much of the effect is presumably lessened by the fact that the rind is necessarily shaved off in preparation for performing the test.

The thermal conductivity is widely variable based on many factors such as test method, test conditions, aging, weathering, density, closed cell content, surface area, pore size, foam chemistry, and spraying conditions. The baseline results are therefore an important and necessary starting point for thermal performance comparison among foam materials. 


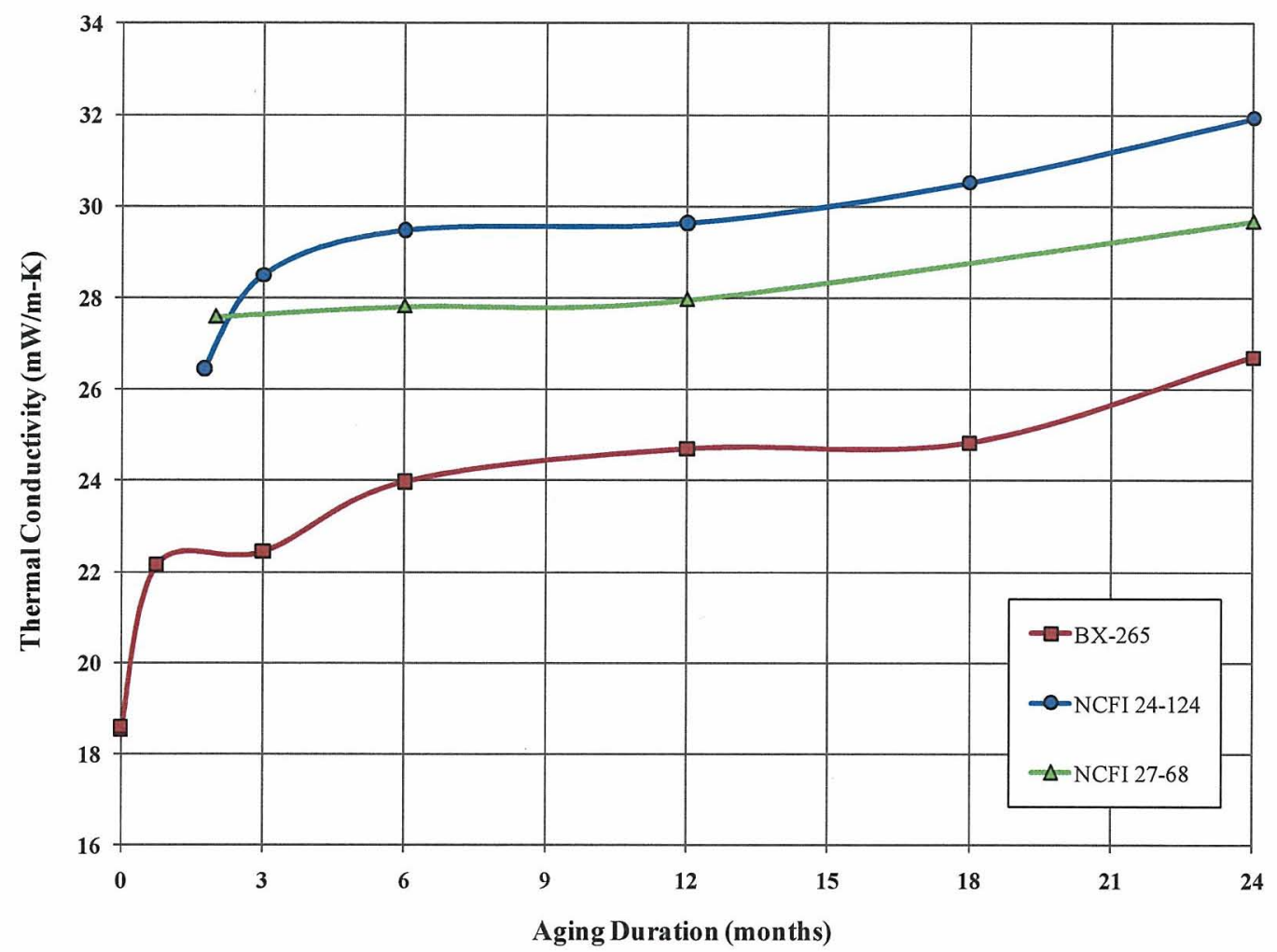

Figure 14. Variation in thermal conductivity with aging duration for SOFI materials BX-265 and NCFI 24-124.

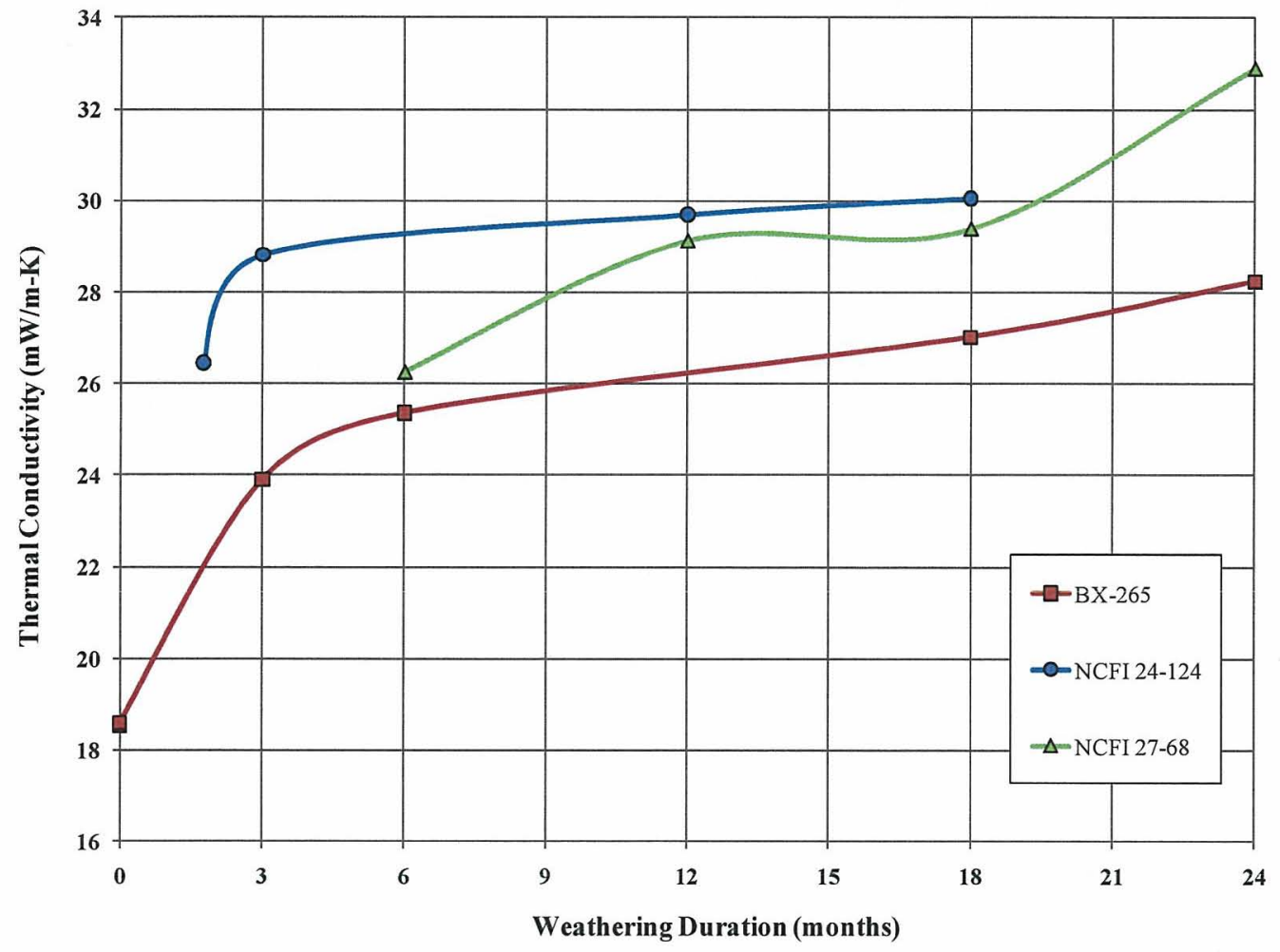

Figure 14. Variation in thermal conductivity with weathering duration for SOFI materials. 


\subsection{Physical Characterization}

The physical characterization tests are used to support the thermal conductivity results and provide basis for future thermal modeling and analysis efforts. The open cell content testing included 43 specimens and a total of 237 tests; the results are summarized in Figures 15 and 16. The open cell content was found to be approximately $6 \%$ for the baseline foam specimens. The average measured open cell contents for the aged and weathered specimens were $10 \%$ and $12 \%$, respectively. The surface area testing included 13 specimens and a total of 112 tests; the results are summarized in Figures 17 and 18. The average surface areas for the baseline specimens were measured to be approximately $130 \mathrm{~m}^{2} / \mathrm{g}$ for the BX-265, $170 \mathrm{~m}^{2} / \mathrm{g}$ for the NCFI 24-124, and 180 $\mathrm{m}^{2} / \mathrm{g}$ for the NCFI $27-68$. The surface area was found to increase by approximately $35 \%$ after three-months of aging or weathering. The surface area then diminished somewhat with further aging but continued to increase with further weathering exposure.

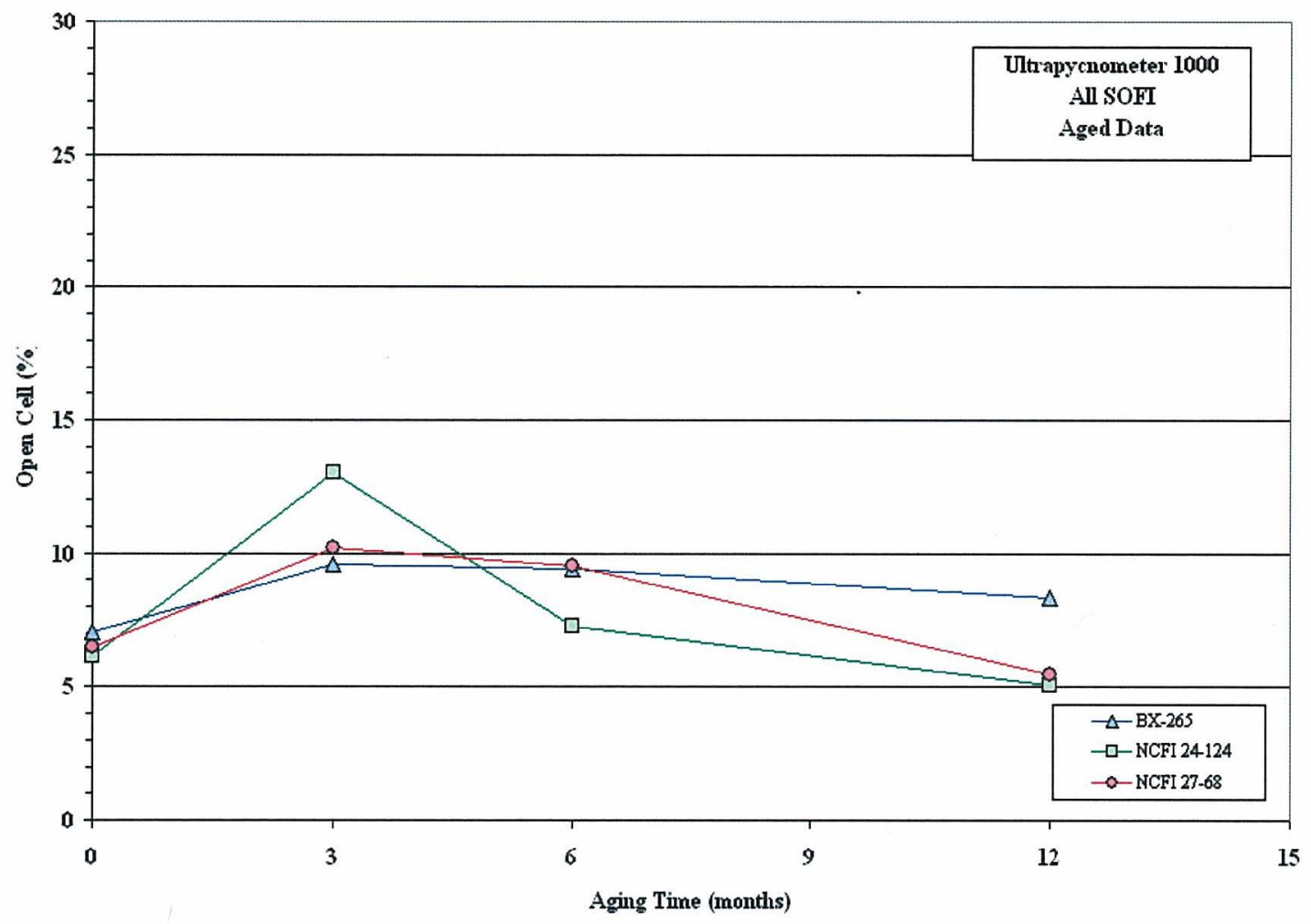

Figure 15. Variation of open cell percentage with aging times for three SOFI materials. 


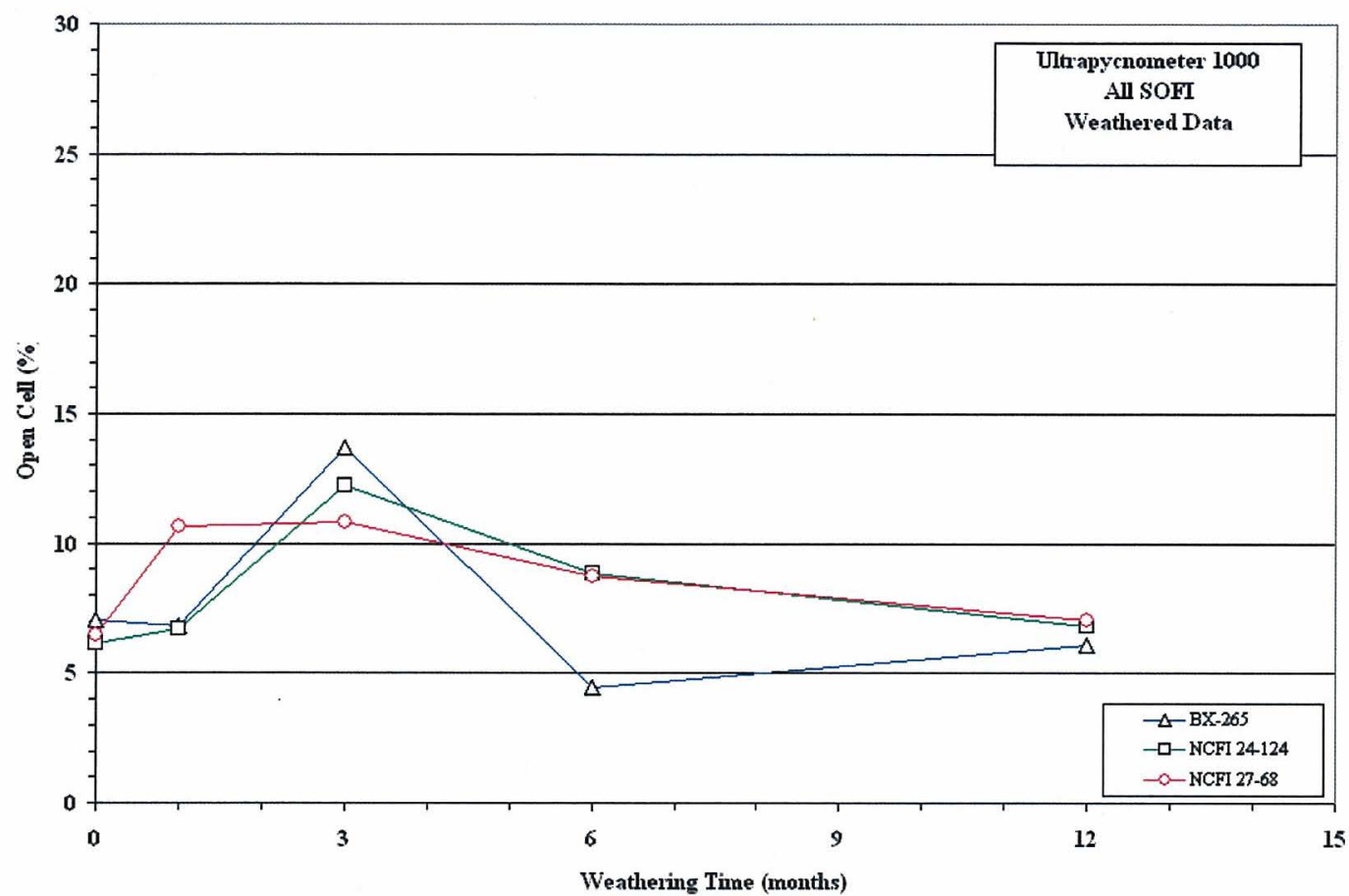

Figure 16. Variation of open cell percentage with weathering times for three SOFI materials.

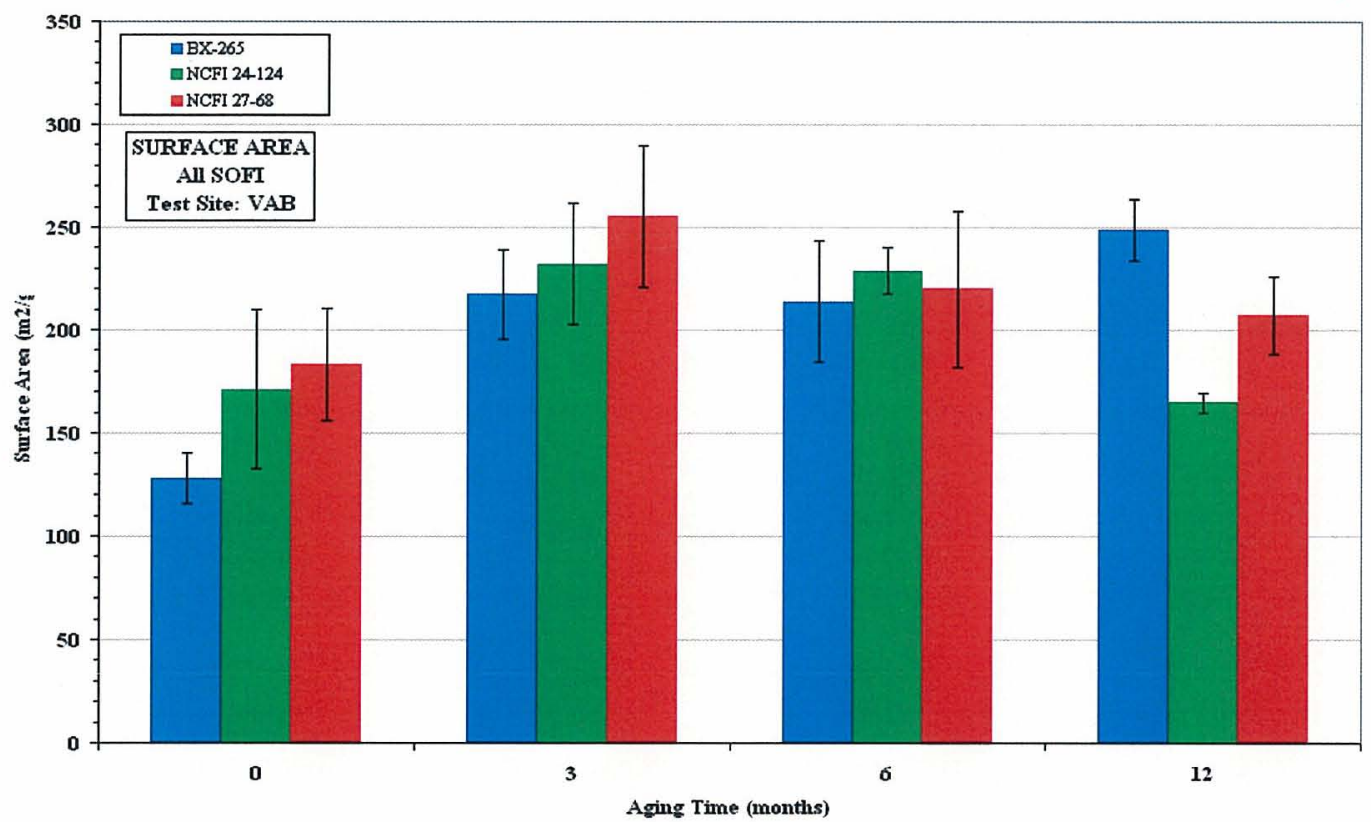

Figure 17. Variation of surface area $\left(\mathrm{m}^{2} / \mathrm{g}\right)$ with aging times for three SOFI materials. 


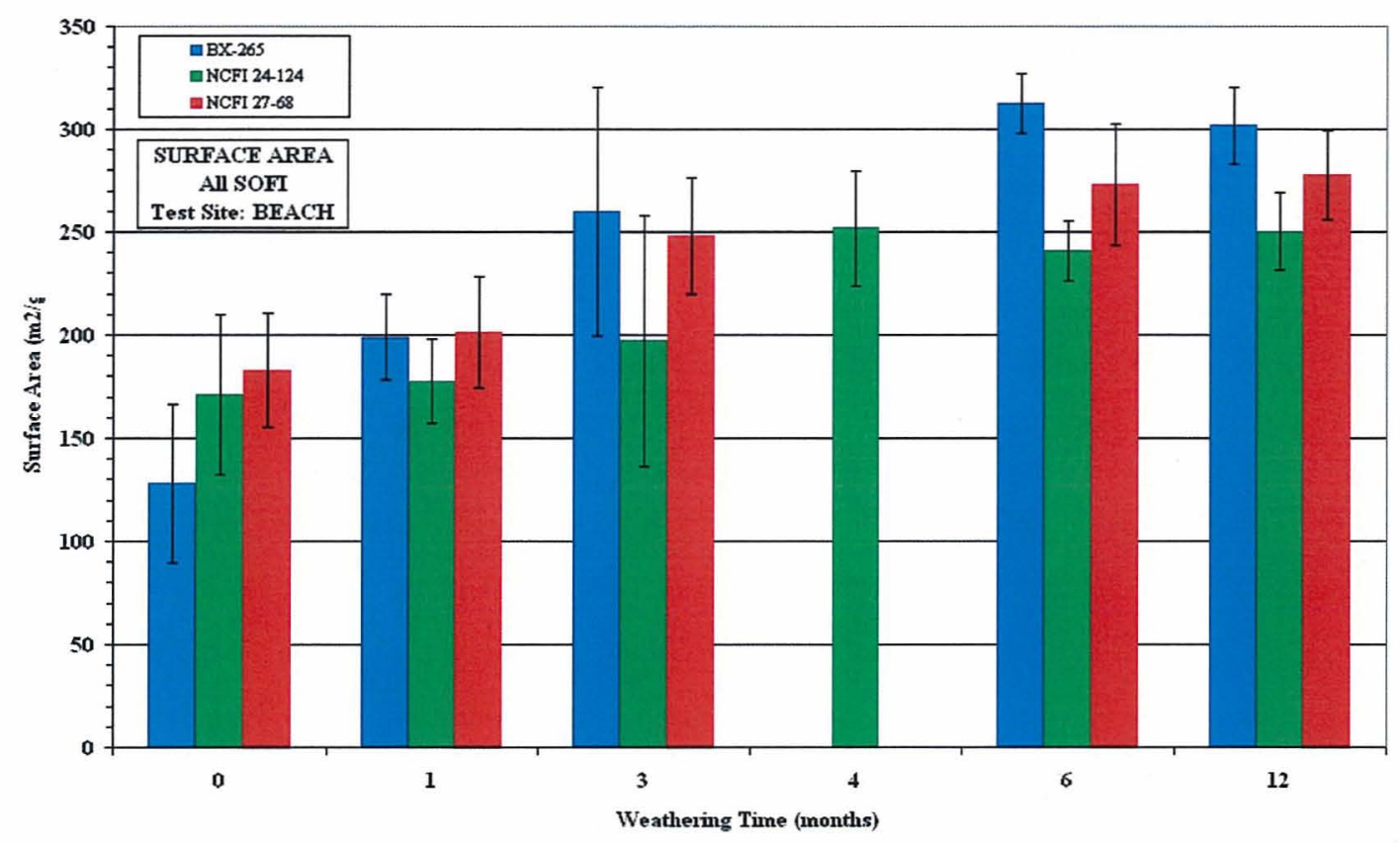

Figure 18. Variation of surface area $\left(\mathrm{m}^{2} / \mathrm{g}\right)$ with weathering times for three SOFI materials.

\section{Discussion and Analysis}

The results from the cryogenic testing part of this thermal performance study of SOFI materials shows that the k-value rises sharply from high vacuum to 10 millitorr as gas conduction begins to dominate the rate of heat transfer. The k-value increased only slightly in the soft vacuum range of 100 millitorr up to 100 torr. The k-value increases significantly from 100 torr to 760 torr, as convection becomes the dominant factor. The alternate acreage foam NCFI 27-68 was the overall best performer in terms of lowest heat transfer. The order of testing, either from no vacuum to high vacuum, or vice versa, was not found to be a factor in cryostat thermal performance testing.

Prior cryostat thermal performance testing on a similar one-meter-long SOFI specimen of BX-250 material (51-mm thickness and a density of $\left.38 \mathrm{~kg} / \mathrm{m}^{3}\right)$ shows a generally similar result to the data presented in this work. ${ }^{15}$ In this case, the k-value was determined to range from 4.1 $\mathrm{mW} / \mathrm{m}-\mathrm{K}$ at 0.1 millitorr to $21.4 \mathrm{~mW} / \mathrm{m}-\mathrm{K}$ at 760 torr. It should be noted that this specimen sprayed, machined, and installed on the cryostat as a single piece rather than two clam-shell halves. Reference data for a similar polyurethane foam tested by the guarded hot plate (under relatively small differential temperatures) was found in the publication by Sparks and Arvidson. ${ }^{16}$ The thermal conductivity is reported as $21.7 \mathrm{~mW} / \mathrm{m}-\mathrm{K}$ at conditions of near ambient pressure and a mean temperature of $186 \mathrm{~K}$. The density of the specimen is $0.032 \mathrm{~kg} / \mathrm{m}^{3}$ which is lower but comparable to the specimens described here. Good agreement for this data point is found for this particular test condition as the cryostat test boundary temperatures provide the same mean temperature. However, experimental test data for the polyurethane foam type of material under the combined conditions of full temperature difference and full vacuum pressure range is not readily found in the literature. 
The results from the ambient testing part of the study show somewhat higher thermal conductivities, as expected, but a marked difference between the close-out foam (BX-265) and the acreage foams (NCFI 24-124 and NCFI 27-68). The BX-265 is the best performer from baseline to any aging or weathering duration. The aged BX-265 increases from roughly 20 to 27 $\mathrm{mW} / \mathrm{m}-\mathrm{K}$ over 24 months while the NCFI 24-124 increases from roughly 24 to $29 \mathrm{~mW} / \mathrm{m}-\mathrm{K}$ over that same period. (The starting thermal conductivity for newly sprayed foams is highly variable in the first 30 days as the curing is fully completed and the excess blowing agent is diffused out of the material.) The three-months weathered thermal conductivities for BX-265 and NCFI 24124 are 24 and $29 \mathrm{~mW} / \mathrm{m}-\mathrm{K}$, respectively.

New information on the intrusion of moisture into SOFI under large temperature gradients was also produced through a related study. Experimental data for a significant number of test specimens were produced and the overall trends are clear. The details of the cryogenic moisture uptake apparatus and complete test results are reported elsewhere. ${ }^{7,17}$ The SOFI materials were found to gain an extraordinary amount of water weight during a cryogenic propellant loading (cold soak) period. Moisture uptake for the NCFI 24-124 specimens (acreage foam) averaged $30 \%$ for the baseline condition and $78 \%$ after 3 months of weathering. Cryogenic moisture uptake continued to increase for both aging and weathering. The weight increase of SOFI was also found to be additive for three consecutive cryogenic thermal cycles, or simulated tanking operations, resulting in as much $167 \%$ weight gain for the one-month weathered acreage foam as shown by the example in Figure 19. The boundary conditions are $295 \mathrm{~K}$ and $78 \mathrm{~K}$ with a $90 \%$ humid environment on warm side. The moisture uptake results are expressed in terms of percentage weight gain for foam materials of similar density. However, much more intensive investigation and analysis is warranted to understand the moisture uptake phenomenon, determine the distribution and morphology of the moisture through the thickness of the foam, and enable suitable engineering analysis of the propulsion performance of space launch vehicles. 


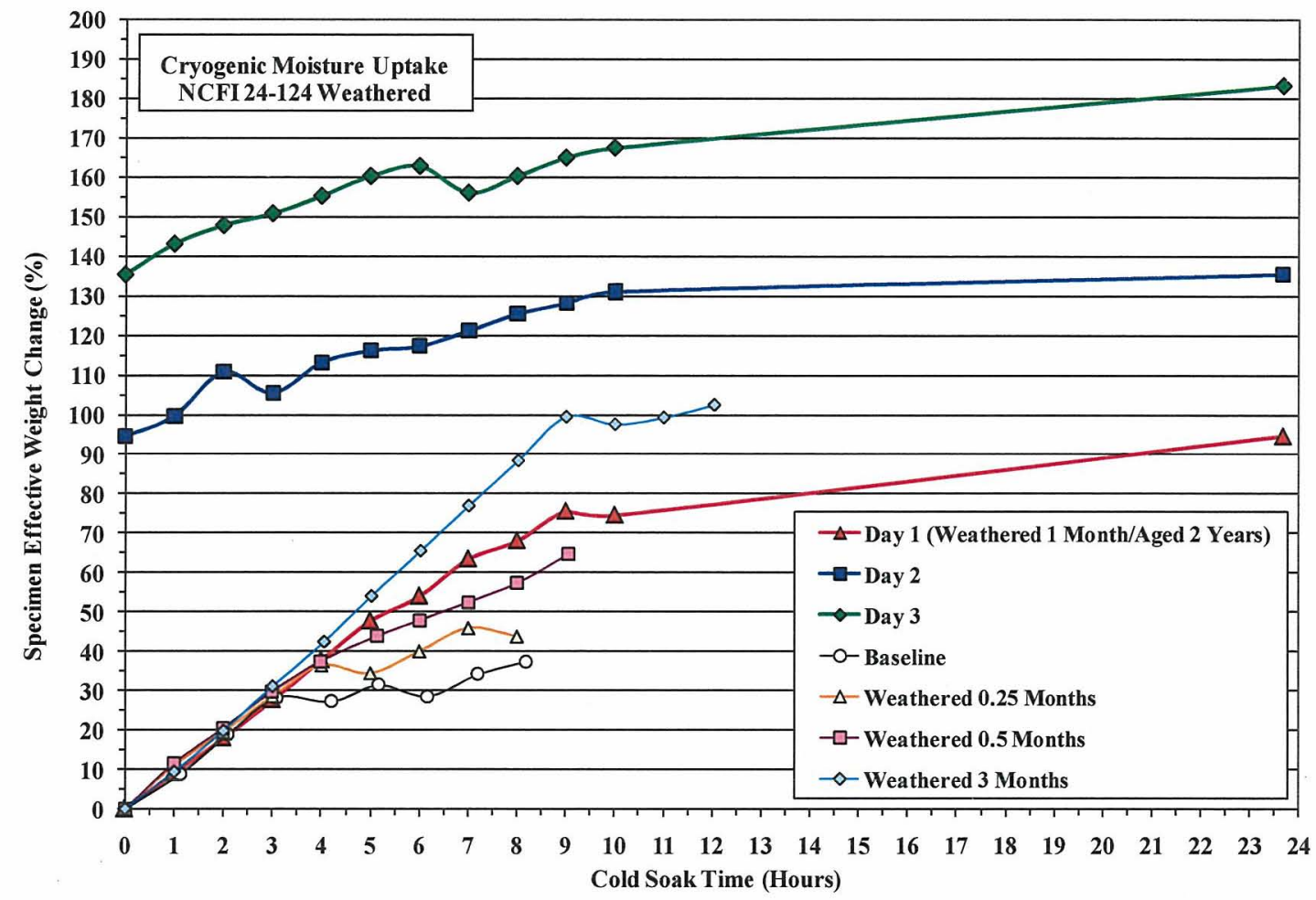

Figure 19. Example of weight gain due to cryogenic moisture uptake in SOFI. Days 1-3 simulate consecutive days of launch vehicle cryogenic tank loading and draining operations.

\section{Conclusions}

Spray-on foam insulation (SOFI), originally developed for use on the cryogenic tanks of space launch vehicles beginning in the 1960s with the Apollo program, has been futher developed through the course of the Space Shuttle program. The Space Shuttle's External Tank uses a number of different insulation materials in a complex system of thermal insulation during cryogenic propellant loading and thermal protection during flight. Presented here are thermal conductivity data for three such SOFI materials under both cryogenic and ambient temperature conditions. New laboratory standard equipment and methods including the Cryostat-100 insulation test instrument were used to produce thermal performance data for actual-use cryogenic-vacuum conditions. ${ }^{18}$ The effect of a rinded (net spray) versus machined outer surface were also examined. Trends for aging and weathering environments were included as part of the ambient test series.

The cryogenic test conditions were representative of the actual-use conditions for most cryogenic insulation systems including those used on the cryogenic tanks and propellant feedlines of space launch vehicles. The test measurements were made at the full temperature difference (approximate boundary temperatures of $78 \mathrm{~K}$ and $293 \mathrm{~K}$ ) and included the full vacuum pressure range. The results are reported in terms of the apparent thermal conductivity (k-value) and the mean heat flux.

This study of the cryogenic thermal performance of SOFI under large temperature differentials provides data and basic new information to apply in the design and optimization of 
future launch vehicles and other cryogenic insulation systems. Many environmental effects and manufacturing details, and operational factors must also be considered in the design and performance analysis for foam insulation systems in dynamic and extreme conditions. The physical characterizations including thermal conductivity, surface area, open cell content must be put together with the actual-use cryogenic thermal performance data and mechanical data to obtain a complete picture of the insulation system performance and design margins.

Work continues to develop modeling techniques based on these new thermal performance data and enable more robust, lighter weight, and higher efficiency foam insulation systems. Future launch vehicles with cryogenic stages will likely use SOFI due to its combination of lightweight, mechanical strength, and low thermal conductivity. Insulation systems for any reusable vehicle still remain a challenge due to the continual breakdown of SOFI with weathering exposure. Spacecraft providing long-duration storage of cryogens in the vacuum of space will likely employ a type of MLI as the primary insulation system. However, these tanks also require a level of thermal insulating performance in the ambient environment during launch preparations and initial flight.

\section{ACKNOWLEDGEMENT}

This work was funded in part by the Space Operations Mission Directorate through the NASA Internal Research and Development (IR\&D) project, Technologies to Increase Reliability of Thermal Insulation Systems. The authors thank Jim Rice and Gweneth Smithers of NASA Marshall Space Flight Center for their support in producing the test articles and Nancy Zeitlin of NASA Kennedy Space Center for guiding this project.

\section{REFERENCES}

1. Scholtens, B.E., Fesmire, J.E., Sass, J.P., and Augustynowicz, S.D., "Cryogenic thermal performance testing of bulk-fill and aerogel insulation materials," in Advances in Cryogenic Engineering, Vol. 53A, American Institute of Physics, New York, 2008, pp. 152-159.

2. Fesmire, J.E., Augustynowicz, S.D., and Scholtens, B.E., "Robust multilayer insulation for cryogenic systems," in Advances in Cryogenic Engineering, Vol. 53B, American Institute of Physics, New York, 2008, pp. 13591366.

3. Coffman, B.E., Fesmire, J.E., Augustynowicz, S.D., Gould, G., White, S., "Aerogel blanket insulation materials for cryogenic applications," Advances in Cryogenic Engineering, AIP Conference Proceedings, Vol. 1218, pp. 913-920 (2010).

4. Fesmire, J.E., "Aerogel insulation systems for space launch applications," Cryogenics, 46, issue 2=3, February 2006, pp. 111-117.

5. Fesmire, J., "Moisture/Aging Study of Spray-On Foam Insulation (SOFI) Under Actual-Use Cryogenic Conditions," executive summary report to NASA Space Operations Mission Directorate, September 2006.

6. Smithers, G., "Technology Development for Thermal Insulation Systems (TIS)," executive summary report to NASA Space Operations Mission Directorate, September 2006.

7. Fesmire, J.E., et al, "Cryogenic Moisture Uptake in Foam Insulation for Space Launch Vehicles," AIAA Space 2008, September 2008. (submitted for publication in Journal of Spacecraft \& Rockets).

8. Anon., Space Shuttle External Tank System Definition Handbook SLWT, Volume 1 - Configuration and Operation, Lockheed Martin Michoud Space Systems, Report No. LMC-ET-SE61-1, December 1997.

9. Rice, J., Certificate of Traceability, DIRR00047, "Moisture/Aging Study of SOFI Under Cryogenic Conditions," Marshall Space Flight Center, 2005. 
10. Anon., "Space Shuttle Production Control, Vertical Products, ET/SRB Matrix History," United Space Alliance Ground Operations.

11. Fesmire, J.E. and S.D. Augustynowicz, "Methods of Testing Thermal Insulation and Associated Test Apparatus," U.S. Patent 6,742,926, issued June 1, 2004.

12. Fesmire, J. E., Augustynowicz, S. D., Scholtens, B. E., and Heckle, K. W., "Thermal Performance Testing of Cryogenic Insulation Systems," Thermal Conductivity, Vol. 29, 2008, pp. 387-396.

13. ASTM C518, "Standard Test Method for Steady-State Thermal Transmission Properties by Means of the Heat Flow Meter Apparatus," ASTM International, West Conshohocken, PA, USA.

14. ASTM D6226, "Standard Test Method for Open Cell Content of Rigid Cellular Plastics," ASTM International, West Conshohocken, PA, USA.

15. Fesmire, J., Augustynowicz, S., and Heckle, W., "Testing of space shuttle spray-on foam insulation under cryogenic vacuum conditions," NASA-TM-2003-211190, pp. 78-79.

16. Sparks and Arvidson, "Thermal and Mechanical Properties of Polyurethane Foams and a Survey of Insulating Concretes at Cryogenic Temperatures," from the Chemical Engineering Science Division of the National Bureau of Standards (NBS) in Boulder, Colorado.

17. Fesmire, J., et al., "Cryogenic Moisture Apparatus," NASA Tech Briefs, May 2010, pp. 5-6.

18. ASTM WK29609, "Guide for Thermal Performance Testing of Cryogenic Insulation Systems," ASTM International, West Conshohocken, PA, USA. 